\title{
APLICATIVO PARA AUXÍLIO E CONTROLE DE CONSULTÓRIO ODONTOLÓGICO POR MEIO DE DISPOSITIVOS MÓVEIS
}

\author{
Amanda Michelle ${ }^{1}$ \\ Vanessa Portella ${ }^{2}$ \\ William Rebeque ${ }^{3}$ \\ Hélio Lourenço Esperidião Ferreira ${ }^{4}$
}

Resumo: A maioria dos consultórios odontológicos atualmente possui algum tipo de programa computacional que ajuda em algumas de suas tarefas burocráticas. Há uma quantidade significativa de sistemas que geram odontogramas no mercado, porém poucos desses softwares são destinados a dispositivos móveis. Objetiva-se com o presente trabalho minimizar este problema, implementando um odontograma que será executado em dispositivos móveis, com o auxílio de tecnologias como PHP, HTML, JavaScript, CSS e o gerenciador de banco de dados MySQL, possibilitando um sistema de rápido acesso que auxiliará o trabalho odontológico na geração de odontogramas, controle de tratamentos, histórico de observações e tratamentos.

Palavras-chave: Odontogramas; Informatização; Aplicativo; Android.

\footnotetext{
1 Direito/Universidade Paulista - UNIP, Brasil. E-mail: amanda.michelleds@gmail.com.

2 Análise e Desenvolvimento de Sistemas/Faculdade Bilac, Brasil. E-mail: vapportella@gmail.com.

${ }^{3}$ Engenharia da Computação/UnIVAP - Universidade do Vale do Paraíba, Brasil. E-mail: williamrebeque@gmail.com.

4 Universidade do Vale do Paraíba, Brasil. E-mail: helio@univap.br.
} 